Aquaculture International

Volume 4, Number 4 / December, 1996 : 325-337

http://dx.doi.org/10.1007/BF00120949

(C) 2006 Springer Science+Business Media
Archimer, archive institutionnelle de l'Ifremer http://www.ifremer.fr/docelec/

\title{
A preliminary study of the behaviour and vitality of reseeded juvenile great scallops, of three sizes in three seasons
}

\author{
P. G. Fleury ${ }^{1,{ }^{*}}$, C. Mingant ${ }^{1}$ and A. Castillo ${ }^{1}$
}

(1) Laboratory Physiologie des mollusques, IFREMER, Centre de Brest, BP 70, 29280 Plouzané, France

*: Corresponding author : Pierre.Gildas.Fleury@ifremer.fr

\begin{abstract}
:
In order to have a better understanding of recessing in great scallop, Pecten maximus and consequently the causes of mortality at reseeding, this study has monitored, at different seasons, the dispersion and recessing of different sizes of juveniles (about 15, 30 and $45 \mathrm{~mm}$, called small, medium and large) after seeding. Moreover, the aim was to see when small spat (15 mm) could be seeded, and thus reduce the costs of intermediate culture.

Three monitoring approaches were used together: (1) continual observations by remote video camera, of a defined area (less than $1 \mathrm{~m} 2$ ) containing 10 scallops from each size group; (2) daily monitoring of behaviour with divers along three bottom lines, with $20 \times 1 \mathrm{~m} 2$ plots each and nine marked scallops per plot; and (3) the biochemical content of the muscle: adenylic energetic charge and storage of energy reserves (glucides, proteins, lipids).

The video monitoring identified but did not quantify predator behaviour, particularly at night. The role and behaviour of spiny crab, Maia squinado, and of small predators has clearly been shown, such as: (a) small crustaceans, Inachus sp., breaking the edges of scallop valves; and (b) small gobies, Pomatoschistus pictus, pecking the tentacles of the scallop mantle.

For the monitoring by divers, filtering appeared much too difficult to look at for it was very disturbed by divers, and anyway the resumption of filtering came immediately after seeding. On the other hand, diver monitoring of dispersal and recessing was quite easy to do with a minimum of practice. On the basis of dispersal, the best seasons for seeding appear to be spring or summer. In autumn, two-thirds of small and medium juveniles are missing 3 days after seeding, but we could not observe whether they had been eaten by predators or had just moved and recessed farther. There was no experiment in winter owing to adverse conditions for scallop seedings.

Biochemical analyses confirmed the unsuitability of autumn for scallop seeding, because of very low glucide content in this season.

The adenylic energetic charge in the smooth part of the muscle showed that stress before seeding (aerial exposure, handling), and post-seeding behaviour (swimming, recessing) have a high energetic cost for scallops. In summer and autumn, 3 days after seeding, none of the three size batches recovered their initial vitality.
\end{abstract}

Keywords: Behaviour - Great scallop (Pecten maximus) - Season - Seeding - Size - Vitality of spat 


\section{INTRODUCTION}

French scallop farming needs three stages : (Dao et al., 1985)

- larval and post-larval rearing in a hatchery-nursery on land, until the size of $2 \mathrm{~mm}$;

- intermediate culture in cages at sea, until juveniles are about $30 \mathrm{~mm}$;

- and extensive on-bottom ongrowing (free life but sedentary) for 2 or 3 years, until scallops reach market size $(10 \mathrm{~cm})$.

Transfer from intermediate culture to on-bottom ongrowing is due to animal growth which would require too many cages for the juveniles. But this transfer brings out rearing stresses, which induce mortality of two-thirds of the animals (Fleury and Dao, 1992).

Predation seems mainly important at seeding, when scallops are not yet large, and are especially weakened by the seeding stress (cages handling, aerial exposure, stacking in tanks), then by the settling in the sediment : energetic cost in swimming (dispersal, escape from predators) and recessing in the sediment. Therefore weak juveniles will find it more difficult to swim, to recess, and so to escape from potential predators (Hatcher et al., in press).

The objective of the work made in 1993 and 1994 in the Bay of Brest was to study seeding stress until the animals recessed (a few days). Except for the quality of animals, the success of seeding depends on juvenile size and on seeding season (Barbeau et al., 1994). The aim was to monitor the seeding stress of three batches of different sizes in three different seasons : spring, summer and autumn. Winter seedings were not advised due to adverse weather conditions.

Because of the cost required to grow scallops from 15 to $30 \mathrm{~mm}$ in intermediate culture cages, there was particular interest in the results of sowing small seed at different seasons.

\section{METHOD}

Behaviour and vitality were studied by different types of monitoring : remote-video, daily observations by divers, and biochemical analysis of animals. Behaviour was studied by two complementary methods, continual recording of a small area $\left(1 \mathrm{~m}^{2}\right)$ with a remote-video, and intermittent observations of three large seedings by divers. The vitality analysis was also studied with two complementary biochemical markers : the storage of energy (glucides, proteins and lipids) in the main part of the muscle, with striated fibres (phasic part), and the tonicity required for sustained closure of the valves (adenylic energetic charge) in the most external part of the muscle with smooth fibers (tonic part). 


\subsection{The progress of the experiments}

The experiments were carried out in the wild, in the cove of Roscanvel in the Bay of Brest (49¹9’40 N - 4³1’45 W ; Fig. 1). This place is shallow (5 to $20 \mathrm{~m}$ ) and sheltered ; the sediment is of slightly muddy sand with some maërl. Different green seaweeds invade the most shallow areas in summer. The benthic fauna is poor : some king scallops (Pecten maximus) and queens (Aequipecten opercularis).

Four experiments of one week duration each were conducted in 1993 and 1994 using one of the coastal oceanographic vessels of IFREMER. The ship offered a strong anchorage with three anchors (needed to hold the video frame) and gave a base for safe equipment and dives. Experiments were conducted as follows :

- Set-up and improvement of methods : 1 week in August 1993 ;

- Behaviour in autumn : 1 week from October 18th to 23rd 1993 (tidal coefficients decreased from 99 to 39); depth $=6$ to $10 \mathrm{~m}$;

- Behaviour in spring : 1 week from April 11th to 15th 1994 (tidal coefficients decreased from 86 to 68 ); depth $=6$ to $10 \mathrm{~m}$;

- Behaviour in summer : 1 week from July 25th to 31st 1994 (tidal coefficients decreased from 95 to 37 ) ; depth $=15$ to $20 \mathrm{~m}$, increased to avoid seaweeds.

Weather conditions were not very different in the three seasonal experiments with wind from the North-East under $12 \mathrm{~m} / \mathrm{s}$ in autumn and spring, and wind from the South-West, later variable, under $8 \mathrm{~m} / \mathrm{s}$ in summer. The sea was calm to moderate, but became choppy with the N.-E. wind.

Bottom water temperature was recorded by a thermograph in August 1993, then taken from divers' thermometers for the three other experiments. It appeared to be very stable throughout each week (variation $<1^{\circ} \mathrm{C}$ ), with $12^{\circ} \mathrm{C}$ in October $1993,10^{\circ} \mathrm{C}$ in April 1994 and $17^{\circ} \mathrm{C}$ in July 1994.

Three batches of different sized juveniles were seeded at each experiment (i.e. each season) : spat of about $15 \mathrm{~mm}$ (except $23 \mathrm{~mm}$ in April 1994) called 'Small', juveniles of standard seeding size (30 mm) called 'Medium' and juveniles kept for more than one year in cages at sea called 'Large' (40 to $45 \mathrm{~mm}$ ). To have a correct simulation of a production seeding, the numbers of seeded scallops have been high : 5000 to 16000 animals per batch, up to 93000 for the 'Small' batch in July 1994. The mean density at sowing was expected to be between 5 and 10 scallops /m2.Table 1 gives the mean sizes, standard deviations in size, and numbers of animals of the different batches. 
Table 1. Sizes and numbers of the different batches.

\begin{tabular}{|lccc|}
\hline batches : & October 1993 & April 1994 & July 1994 \\
'Small' : & & & \\
Mean size (mm) & $\mathbf{1 4 . 9}$ & $\mathbf{2 3 . 4}$ & $\mathbf{1 2 . 9}$ \\
St. deviation (mm) & 4.3 & 3.8 & 2.3 \\
Numbers of animals & 16500 & 15000 & 93000 \\
& & & \\
'Medium' : & & & \\
Mean size (mm) & $\mathbf{2 9 . 2}$ & $\mathbf{2 8 . 3}$ & $\mathbf{3 5 . 8}$ \\
St. deviation (mm) & 3.6 & 4.3 & 5.3 \\
Numbers of animals & 15700 & 9000 & 10800 \\
& & & \\
'Large' : & & & $\mathbf{4 3 . 6}$ \\
Mean size (mm) & $\mathbf{4 2 . 8}$ & 4.4 & 5.6 \\
St. deviation (mm) & 4.6 & 5400 & 11000 \\
Numbers of animals & 7000 & & \\
& & &
\end{tabular}

\subsection{Behaviour monitoring at seeding (Fig. 2).}

Video observations were continually recorded from the ship with a time-lapse video-recorder set at 4 frames per second (i.e. reduced to one sixth speed). The OSPREY camera was set up vertically one meter off the bottom on a metal frame with adjustable feet. Ten scallops from each batch (selected for their whitish colour) were seeded by divers under the camera (i.e. 30 scallops in less than $1 \mathrm{~m}^{2}$ ). Several hundred scallops from the three sizes were sown around (at a density of about 5 to 10 animals $/ \mathrm{m} 2$ ).

Plot recording with the underwater hand camera was abandonned after the first experiment (set-up, August 1993) for it did not give good enough resolution for monitoring.

Three separate seedings of 5000 to 16000 scallops each (except for the batch of 93000 'Small' in summer 1994) were made at each experiment (i.e. each season), and observed by divers every of the four first days. Divers worked along a transect line as shown in Fig. 2, recording the behaviour and position of each scallop in each of 60 plots of $1 \mathrm{~m} 2$ (20 plots per batch). In the first experiment seedings were undertaken using standard conditions (from the surface over the sampling plots) but this random dispersion gave a range of density too much large ( 0 to 50 juveniles $/ \mathrm{m}^{2}$ ) for further efficient observations. Therefore we disregarded the initial density effect and surveyed plots seeded by divers with a standard density of 9 scallops $/ \mathrm{m}^{2}$. Nevertheless around the plots the dispersion of other scallops seeded from the surface remained random. The lack of a mark on the scallops in the set-up experiment proved also to be 
a serious handicap to monitor individual animals. The marking of scallops with a black felt-pen was chosen in further experiments as it was quick, low stressing and remained visible over a week. Marked scallops were initially spaced regularly on the plots, the other scallops seeded from the surface being removed from the plots. Therefore the density in the plots was invariable (9 animals /m2) but not really different from the one surrounding (5 to 10 scallops /m2).

The behaviour of each marked scallop was observed as follows :

- Recessing : scallop upside down, just laid, vertical, half-recessed or recessed ;

- Dispersal : did scallop staid in place, just moved in the plot or was missing ?

- Predation : divers reported the genus of predators observed in the plots, and whether dead shells where entire or more or less broken.

Observations of the filtering stages, as used by Ø. Strand in Norway for tank monitoring of scallops stressed by brackish water (Strand et al., 1993), were abandonned after the first experiment, since many animals just closed as the divers approached, and a daily observation was not enough to show differences in the juvenile vitality.

The two methods, remote video and diver observations, appear complementary (Table 2).

Table 2: Complementary uses in remote-video and diver observations.

$$
(+) \text { pros } \quad(-) \text { cons }
$$

\begin{tabular}{|c|c|c|}
\hline & REMOTE-VIDEO & DIVERS \\
\hline $\begin{array}{l}\text { Frequency of } \\
\text { observations }\end{array}$ & $\begin{array}{l}(+) \text { continual recording } \\
\text { (slow motion possible) }\end{array}$ & intermittent observations \\
\hline $\begin{array}{l}\text { Samples } \\
\text { observed }\end{array}$ & $\begin{array}{l}\text { (-) } 1 \text { mixed sample } \\
\text { three batches x } 10 \text { scallops } / 1 \mathrm{~m}^{2}\end{array}$ & $\begin{array}{l}\text { three separate sowings } \\
20 \mathrm{~m}^{2} \text { of sowing }\end{array}$ \\
\hline $\begin{array}{l}\text { Clarity of } \\
\text { observation }\end{array}$ & $\begin{array}{l}(-) \text { difficult to see small scallops } \\
\text { which are recessed }\end{array}$ & $\begin{array}{l}\text { observations demanding } \\
\text { just a few practice }\end{array}$ \\
\hline $\begin{array}{l}\text { Disturbance of } \\
\text { animals }\end{array}$ & $\begin{array}{l}\text { (+) infra-red at night } \\
\text { (-) increased density } \\
\text { (-) frame of the video-caméra }\end{array}$ & $\begin{array}{l}\text { shifting by divers } \\
\text { lamp at night }\end{array}$ \\
\hline Sample taking & (-) impossible & possible \\
\hline
\end{tabular}




\subsection{The biochemical survey of vitality.}

The juvenile vitality at seeding was measured by studying the energetic capacity of the animals at different times along the seeding stress. For the scallop is able to swim and recess with quick muscle contractions, it was convenient to measure the quality in the muscle.

Moal et al. (1987) have shown the usefulness of the adenylic energetic charge (A.E.C.) to evaluate Pacific oyster (Crassostrea gigas) vitality. The A.E.C. is defined as the ratio between the adenylic nucleotides with rich energy (ATP and ADP) and the whole adenylic pool, according to the relation :

$$
\begin{array}{cc}
\text { ATP }+1 / 2 \text { ADP } & \text { ATP }=\text { Adenosine Tri-Phosphate } \\
\text { A.E.C. = } & \text { with } \\
\text { ATP }+ \text { ADP + AMP } & \text { ADP }=\text { Adenosine Di-Phosphate }
\end{array}
$$

In theory this ratio can range from 0 if all nucleotides are without energy (AMP) to 1 if they are all ATP (maximum of energy).

In adult scallops, Le Coz (1989) has shown that the energetic charge in the muscle is very high (0.93 in average) with a very little dispersion between animals (s.d. $=0.006)$ compared to other organs, and remains very stable during aerial exposure (Fig. 3). Some complementary analyses in juveniles by us have shown that it was especially the large phasic portion of the adductor muscle, with striated fibres, which maintains a high A.E.C. In the more external tonic portion of the adductor muscle, with smooth fibres allowing the sustained closure of the valves, the A.E.C. appeared to be more variable. Therefore we separated the biochemical analysis into two parts :

- storage of energy reserves (glucides, proteins, lipids) in the striated part of the muscle,

- A.E.C. in the smooth part.

Samples (10 scallops each only) were taken at different times of seeding : from cages, before seeding (4 hours of aerial exposure), at day +1 after seeding and at day +3 (even at day+24 in the summer experiment).

Analysis of energy reserves in the striated muscle were made from freeze-dried matter. Glucides were measured according to Dubois's method (Dubois et al., 1956), proteins were measured according to Lowry's method (Lowry et al., 1951) with an automatic analyser, and lipids were measured with the gravimetric method described by Moal et al. (1985). 
Analysis of A.E.C. in the smooth muscle were made with 'high performance liquid chromatography' (HPLC) after storage in liquid nitrogen, according to the method described by Moal et al. (1989).

\section{RESULTS}

\subsection{The remote-video : predators}

The remote video was shown to have some limitations : with one camera at one metre off the sediment we could only record less than one $\mathrm{m} 2$ and the number of animal wase very low ; if the density was increased it would differ from a standard seeding, and juveniles would move away. In addition the definition and contrast were not good enough to monitor animal behaviour, especially on plots with 'Small' juveniles even if they were whitish in colour. Problems were also encountered with holding the frame against the current when tide coefficients were over 70 (mean and spring tides) or when the site was no longer sheltered from the wind. However, the remote video was still used in the following experiments for its complementary aspects with divers, overall in continual monitoring of predators.

The remote-video identified predator activity, especially at night (attractive effect of the light), but did not quantify it (artefacts of the frame and light). In addition to the action of the spiny crab (Maia squinado), the role and behaviour of small unrecognized predators was clearly observed such as :

- small crustaceans (Inachus sp.) breaking the edge of scallop valves ;

- small gobies (Pomatochistus pictus) pecking the tentacles of the scallop mantle.

These predators were also observed during the day by diving, as far as some starfish (Asterias rubens) and velvet crabs (Necora puber).

\subsection{The divers' observations : dispersal and recessing}

In contrast, direct observation of recessing and dispersal recorded by divers proved to be quite easy but required a minimum of practice to avoid a disturbance of the animals.

The divers surveyed a large number of animals : 20 plots $\times 9$ juveniles each $=180$ scallops per batch, that is to say 540 per experiment. These scallops were regularly and individually observed. Appreciable differences appeared between batches according to size and season, 
although these results have to be considered according to the weather conditions and the initial vitality of each batch.

With regard to dispersal of animals, the best seeding periods were clearly spring and summer, even for the 'Small' scallops (size of $23 \mathrm{~mm}$ in spring and $13 \mathrm{~mm}$ in summer). In autumn two thirds of the 'Medium' and of the 'Small' juveniles disappeared three days after seeding (Fig. 4), and we could not distinguish between mortality (with the empty shells rapidly moved away by the current), passive dispersion (weak scallops carried away) or active swimming (to escape from predators or to find a more suitable place to recess).

With regard to speed of recessing, measured after scallops which remained in plots, there were few differences between the juveniles in autumn (yet dispersal is greatest in this season) : all batches had a quick recessing, over $80 \%$ after one day,. In spring and summer, 'Medium' juveniles had a quick recessing too, $80 \%$ as well after one day, and appeared to recess better than 'Large' animals, about 60\% after one day. As for 'Small' spat, recessing appeared correct in spring and autumn, but very slow in summer with only 39\% after two days (Fig. 5).

\subsection{The biochemical analysis : loss of vitality at seeding.}

Analysis of the energetic charge in smooth muscle showed that A.E.C. was lower in the 'Small' batch. The analysis also showed that loss of energy persists after seeding (Fig. 6) but batches were too small to show a significant difference.

The seasonal variations in the energy storage of the muscle (glucides, proteins and lipids) could be analysed only in 'Large' and 'Medium' juveniles for there were no meat enough in muscles of 'Small' spat. They essentially showed a clear drop of glucide content in autumn (Fig. 7). Proteins remained around 50-60\% of dry matter in average (Fig. 8) and lipids around 4-5\% (Fig. 9).

\section{DISCUSSION.}

The remote video recording identified predators and their behaviour. But it was of very little value for studying recessing and dispersal of scallops because of the small batch size and poor quality of the pictures.

Renewal of filtering after seeding could not be observed in the wild.

But diver monitoring of recessing and dispersal of animals gave useful results, even if required numerous means which limited repetition of the experiments. Results were sufficient to 
identify that most dispersal occured in autumn and that recessing was size dependant in spring and summer. This needs further experiments in laboratory.

The biochemical analysis of the storage reserves in muscle corroborated the autumnal problem with the lack of glucides in this season.

The A.E.C. in smooth muscle showed that vitality is lower in 'Small' juveniles (but we cannot exclude artefacts, such as defrostings, at this very small size). Loss of vitality seemed to persist after the seeding, but has to be confirmed by a specific study with more numerous batches for a significant statistical treatment.. Anyway, when juveniles have recessed, they need a recovery period before being able to suffer new stresses such as unearthing by gales, predator attacks or dredge passing-by. The length of this recovery to the initial energetic level remains to be specified. However the A.E.C. analysis is difficult and lethal which excludes an individual monitoring of animals. Further studies would be made easier with a more simple, individual and non lethal index of vitality. Such physiological indices are now being studied.

The utility of seeding small juveniles in spring and summer will be studied further in 1995. The survey will monitor different seedings of the same batch according to different periods of the year (i.e. and different sizes due to summer growth of the spat).

Sediment texture, which may make the recessing of the scallops easier or harder, has also to be studied further, for our results from Roscanvel cove with sandy-muddy sediment can only be transferred to similar places.

\section{REFERENCES.}

Barbeau, M.A., Scheibling, R.E., Hatcher, B.G., Taylor, L.H. and Hennigar, A.W. (1994). Survival analysis of tethered juvenile sea scallops (Placopecten magellanicus) in field experiments : effects of predators, scallop size and density, site and season. Marine Ecology Progress Series 115, 243-256.

Dao, J.C., Buestel, D., Gérard, A., Halary, C. and Cochard, J.C. (1985). Le programme de repeuplement de coquilles Saint-Jacques (Pecten maximus L.) en France : finalité, résultats et perspectives. Colloque franco-japonais d'océanographie. Marseille septembre 1985.

Dubois, M., Gilles, K.A., Hamilton, J.K., Rebers, P.A., and Smith, F. (1956). Colorimetric method for determination of sugars and related substances. Analytical Chemistry 28, 350356. 
Fleury, P.G. and Dao, J.C. (1992). De la pêche à l'aquaculture : l'élevage de la coquille SaintJacques. Equinoxe 38, 20-27.

Hatcher, B.G., Scheibling, R.E., Barbeau, M.A., Taylor, L.H., Hennigar, A.W. and Windust, A. (in press). Mortality and dispersion of juvenile sea scallops (Placopecten magellanicus) seeded in a tidal channel. Canadian Journal of Fisheries and Aquatic Sciences.

Le Coz, J.R. (1989). La charge énergétique adénylique : mise au point, application à trois mollusques bivalves, synthèse et perspectives. Mémoire IFREMER /Direction des Ressources Vivantes. 85 p.

Lowry, O.H., Rosebrought, N.J.,Farr, A.L. and Randall, R.J. (1951). Protein measurement with the folin phenol reagent. Journal of Biology and Chemistry. 193, 265-275.

Moal, J., Samain, J.F. Le Coz, J.R., and Daniel, J.Y. (1985). Protéines, glucides, lipides particulaires : aspects méthodologiques. Océanis, 11(5),498.

Moal, J., Le Coz, J.R., Samain, J.F. and Daniel, J.Y. (1989). Nucleotides in Bivalves : extraction and analysis by high-performance liquid chromatography (HPLC). Comparative Biochemistry and Physiology, 93 B (2), 307-316.

Moal, J., Samain, J.F., Bodoy, A. and Le Coz, J.R. (1987). Approche de l'état physiologique de l'huître creuse (Crassostrea gigas) au cours d'un cycle saisonnier à Marennes-Oléron. Haliotis 16, 497-511.

Strand, Ø., Solberg, P.T., Andersen, K.K. and Magnesen, Th. (1993). Salinity tolerance of juvenile scallops (Pecten maximus) at low temperature. Aquaculture 115, 169-179. 


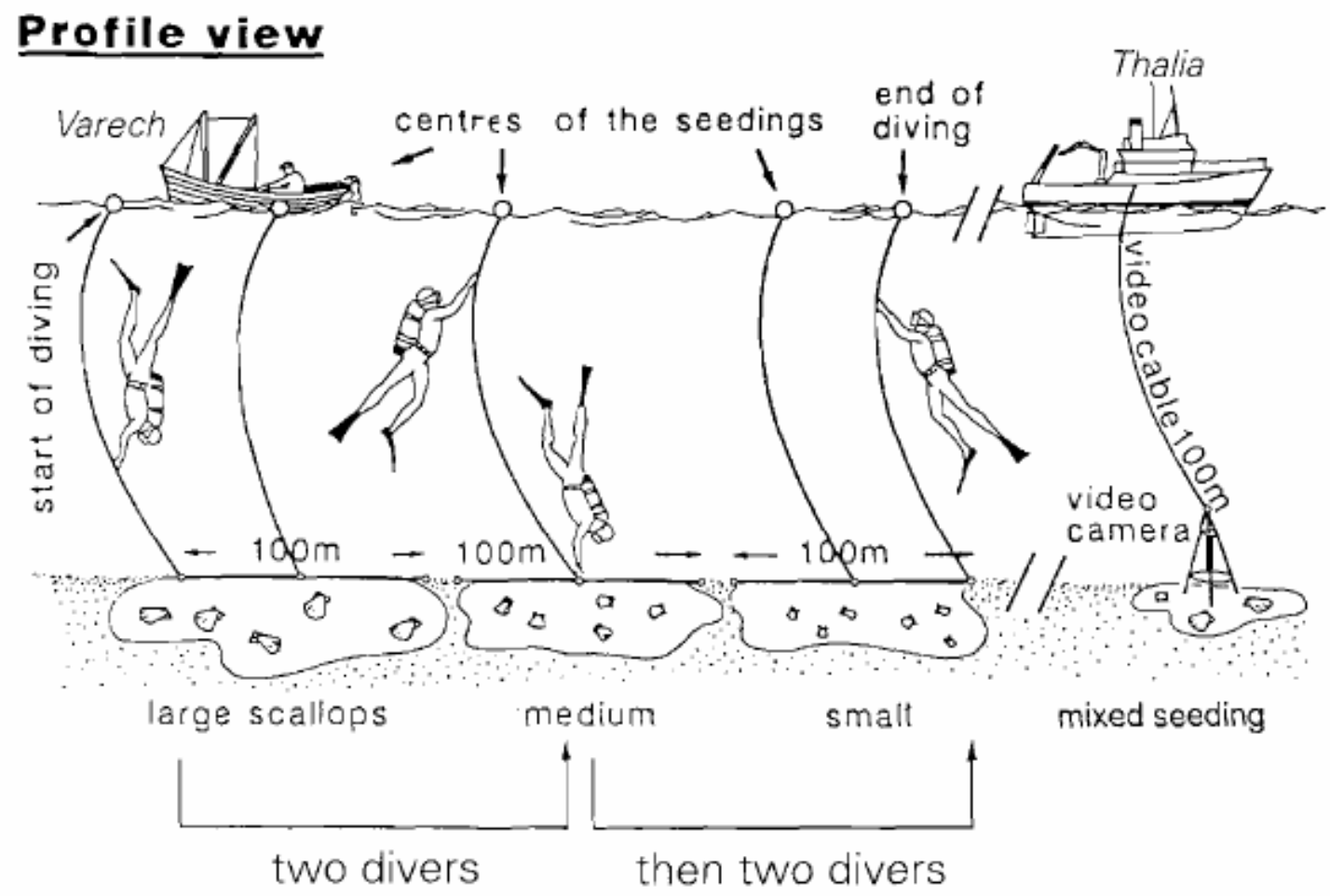

\section{Plan View}
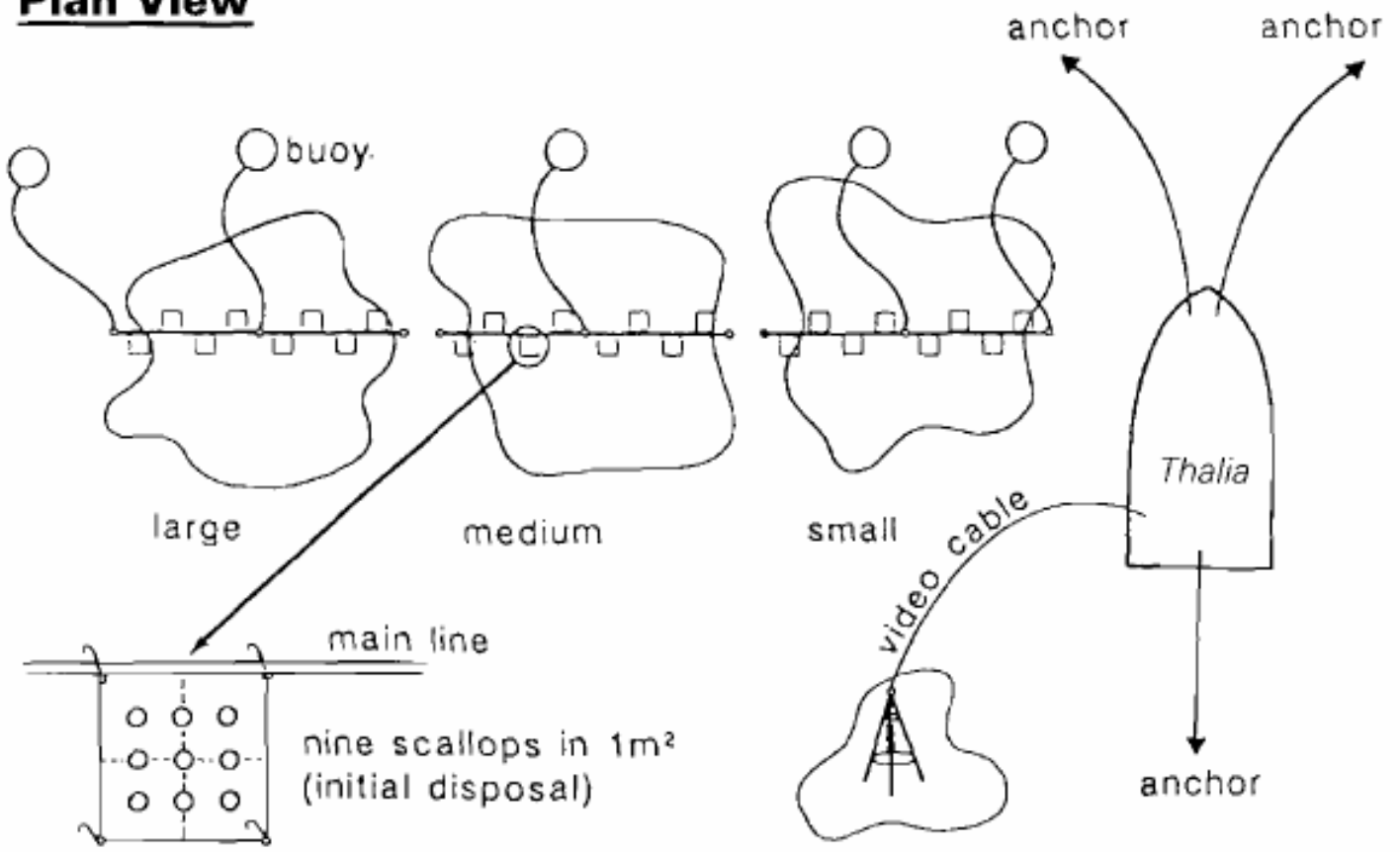

mixed seeding

Fig. 1 Experimental installations for the monitoring of scallop reseeding in the Bay of Brest. 


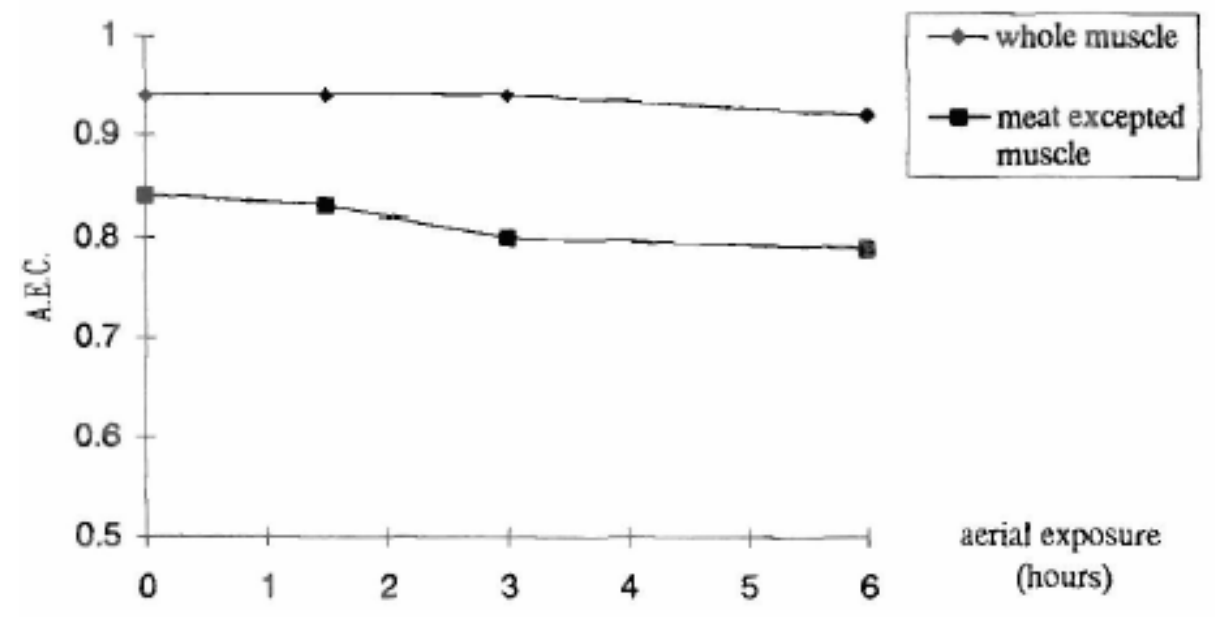

Fig. 2. Effect of anoxia on the energetic charge in Pecten maximus (after Le Coz, 1989). 


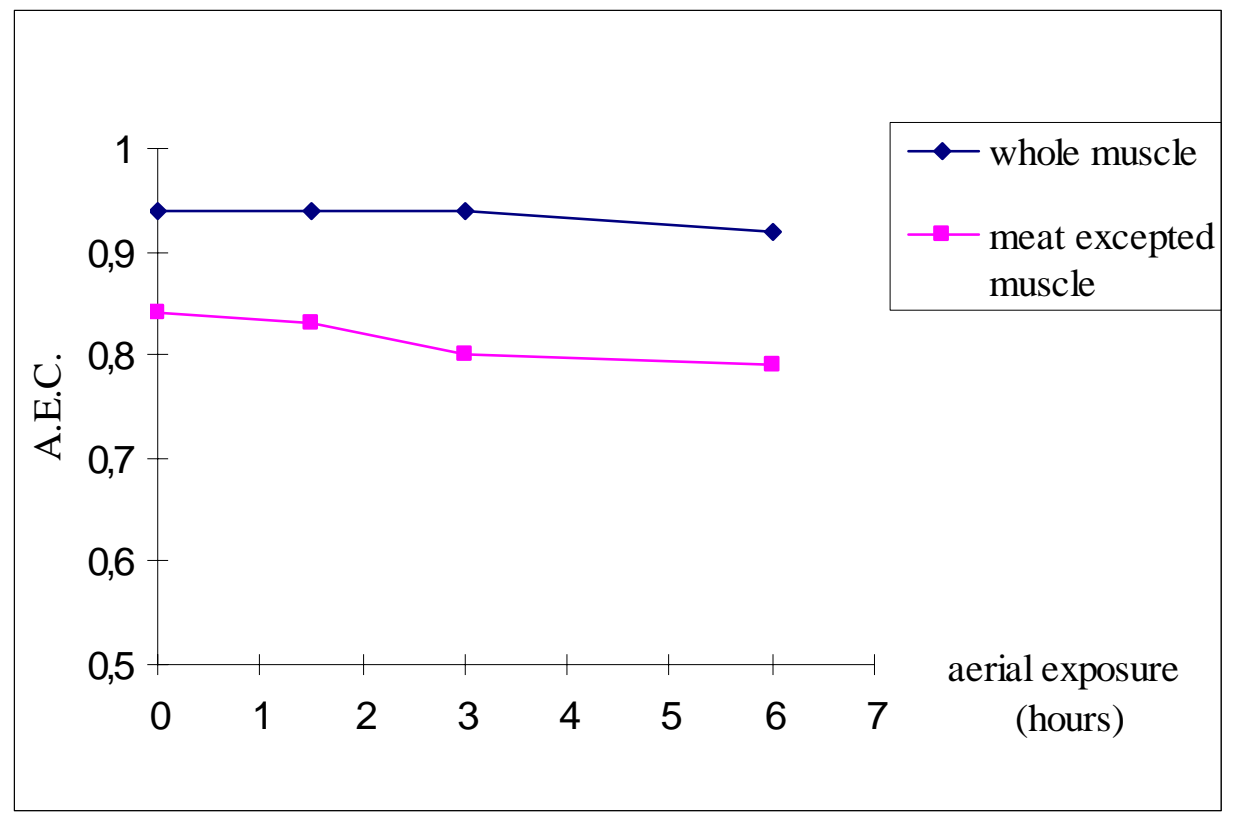

Fig. 3. Effect of anoxy on the energetic charge in Pecten maximus.

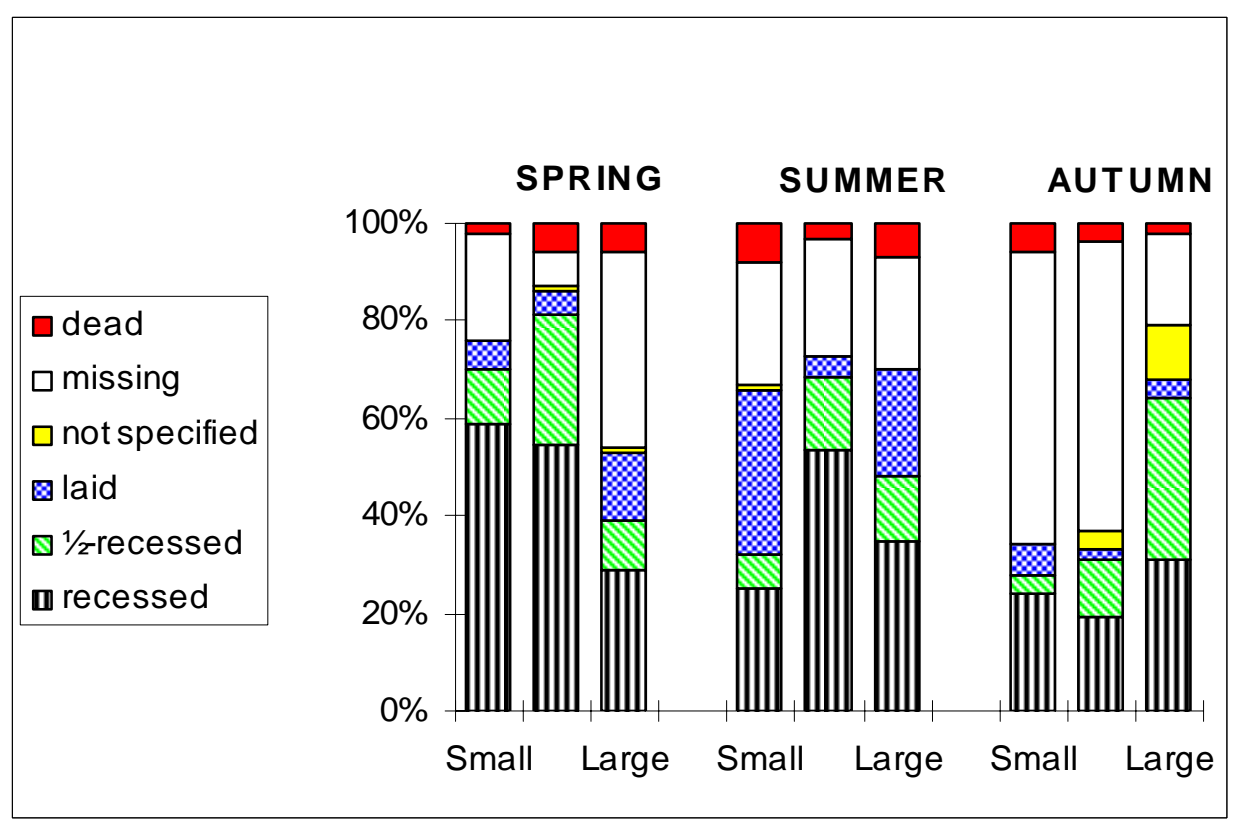

Fig. 4. Dispersal and recessing of scallop juveniles three days after seeding. 


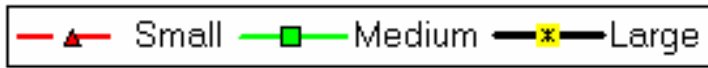

SPRING

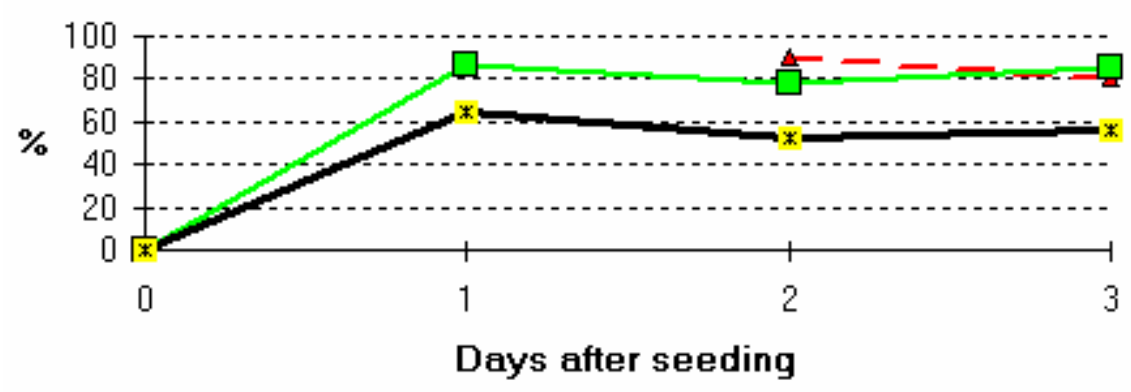

SUMMER

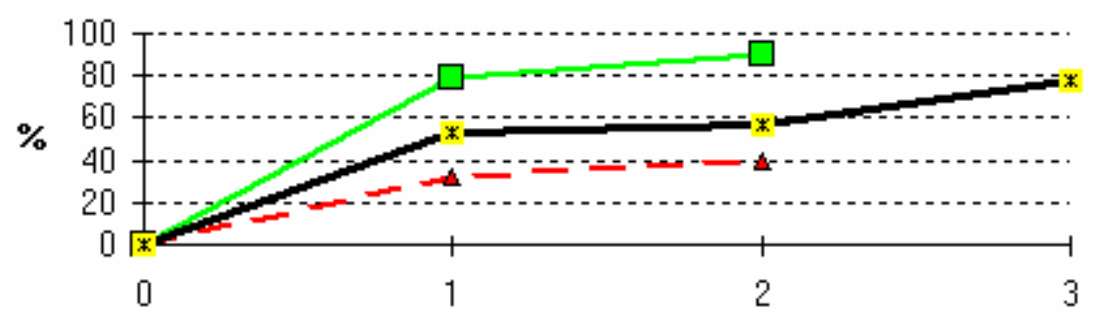

Days after seeding

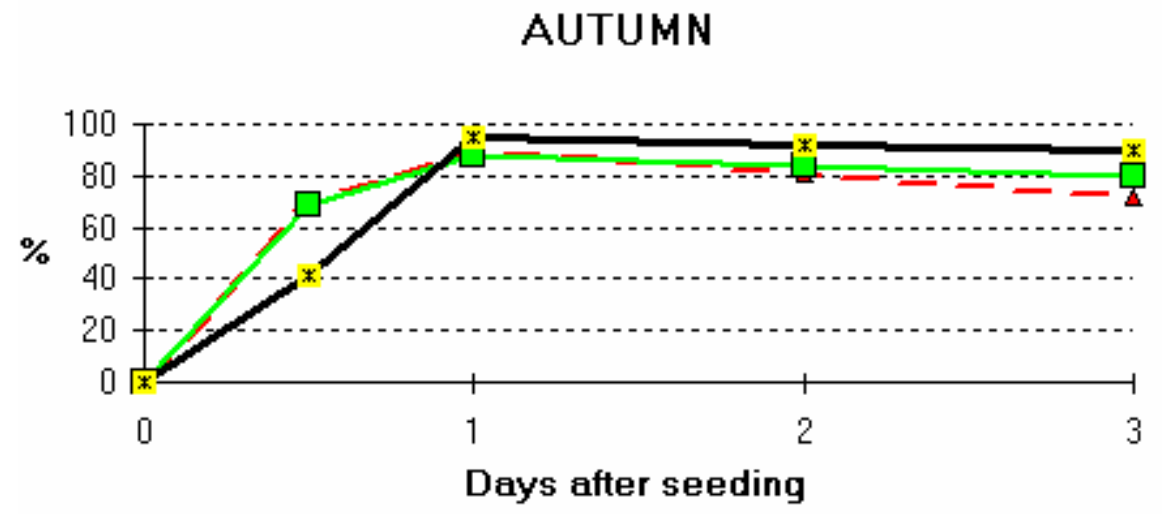

Fig. 5. Recessing monitoring of juvenile scallops.

according to total number of scallops which have not moved from the plots $\mathrm{N}=221$ (Spring) 


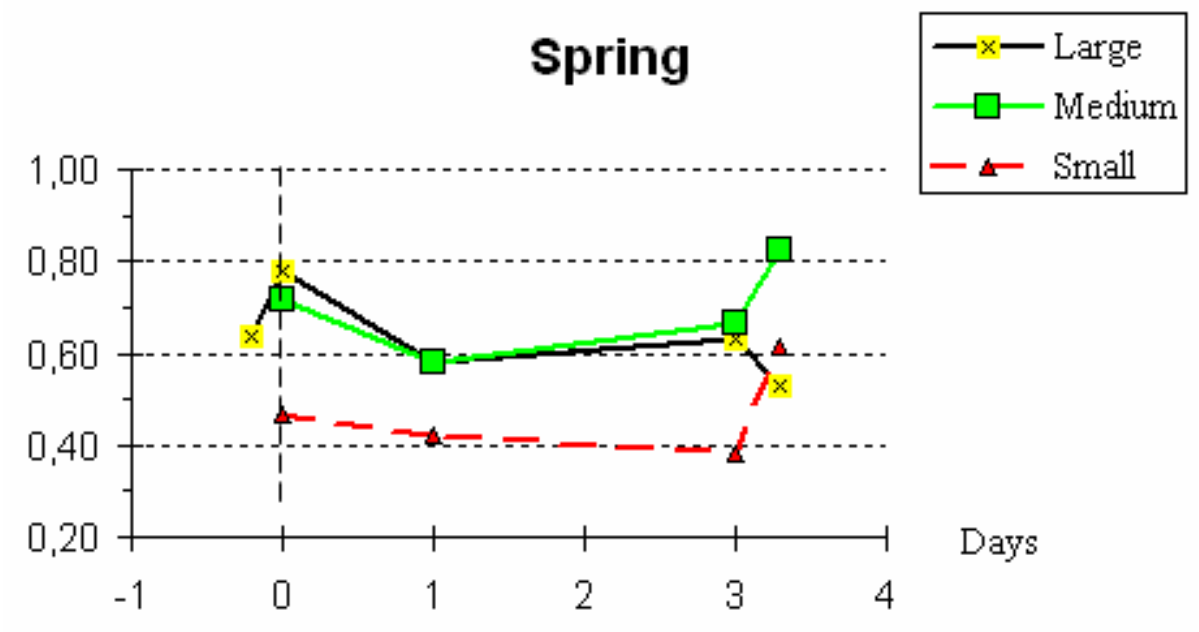

\section{Summer}

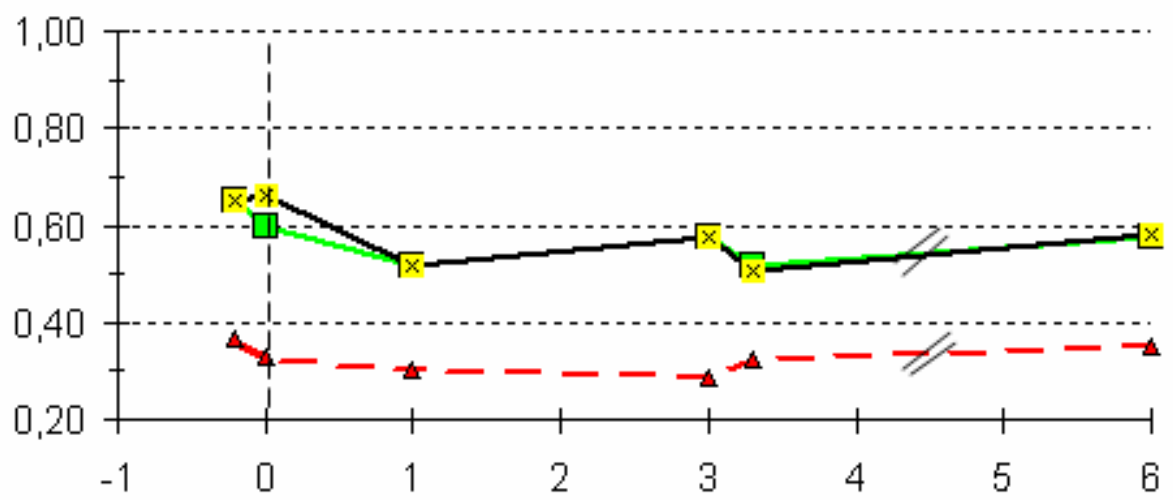

Autumn

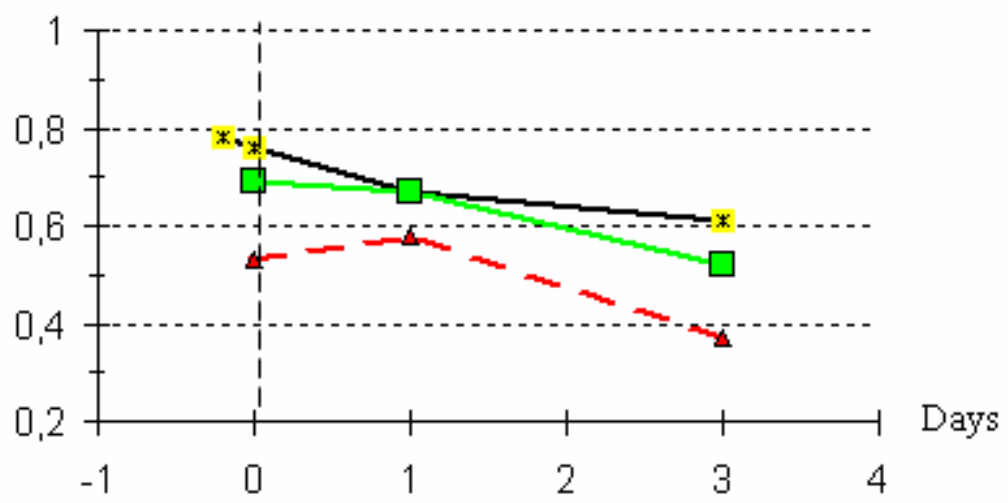

Fig. 6. Evolution of the A.E.C. at seeding in the smooth muscle of scallop juveniles. (D0 = seeding ; $\mathrm{R}=$ recessed scallop) 


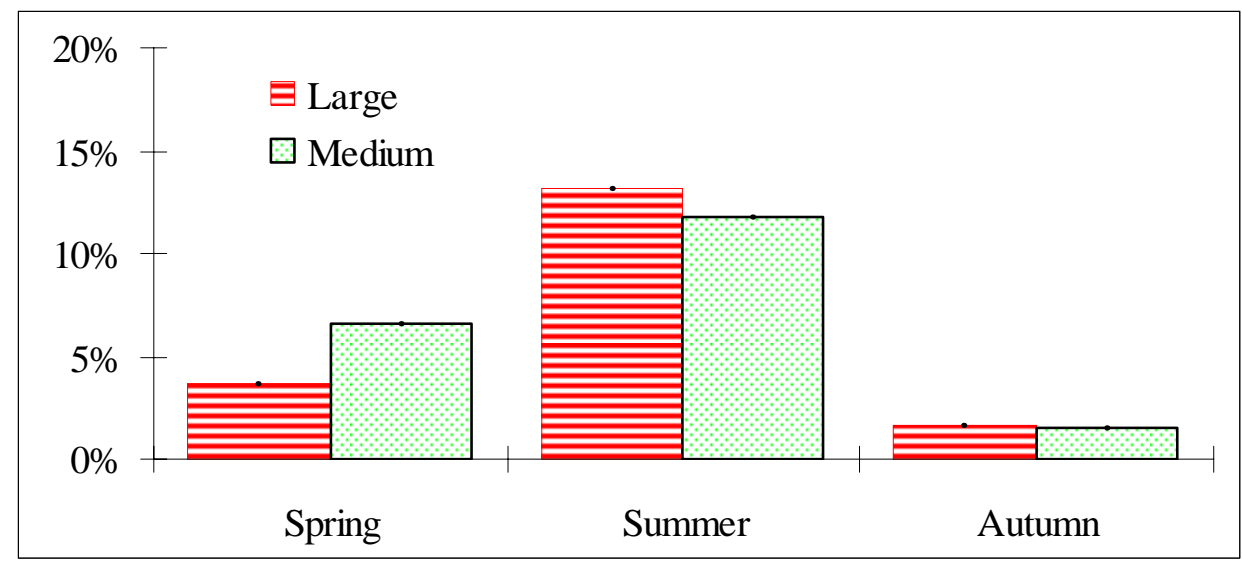

Fig. 7. Glucide content in the striated muscle of scallop juveniles according to the season with standard deviation. $\mathrm{N}=10$ /batch

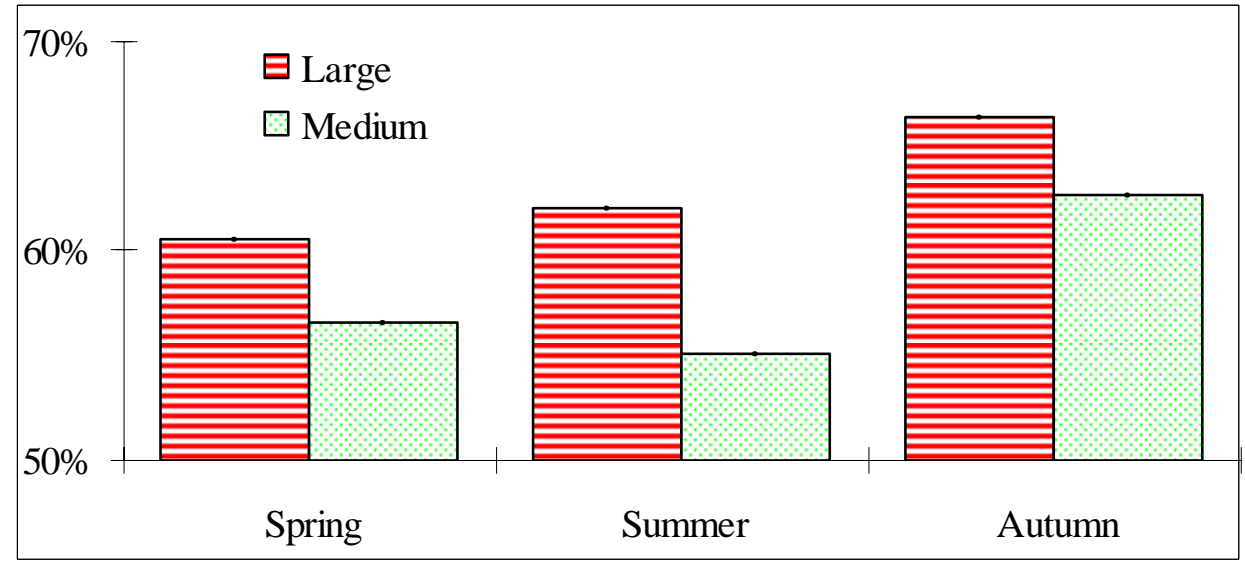

Fig. 8. Protein content in the striated muscle of scallop juveniles according to the season with standard deviation. $\mathrm{N}=10$ /batch

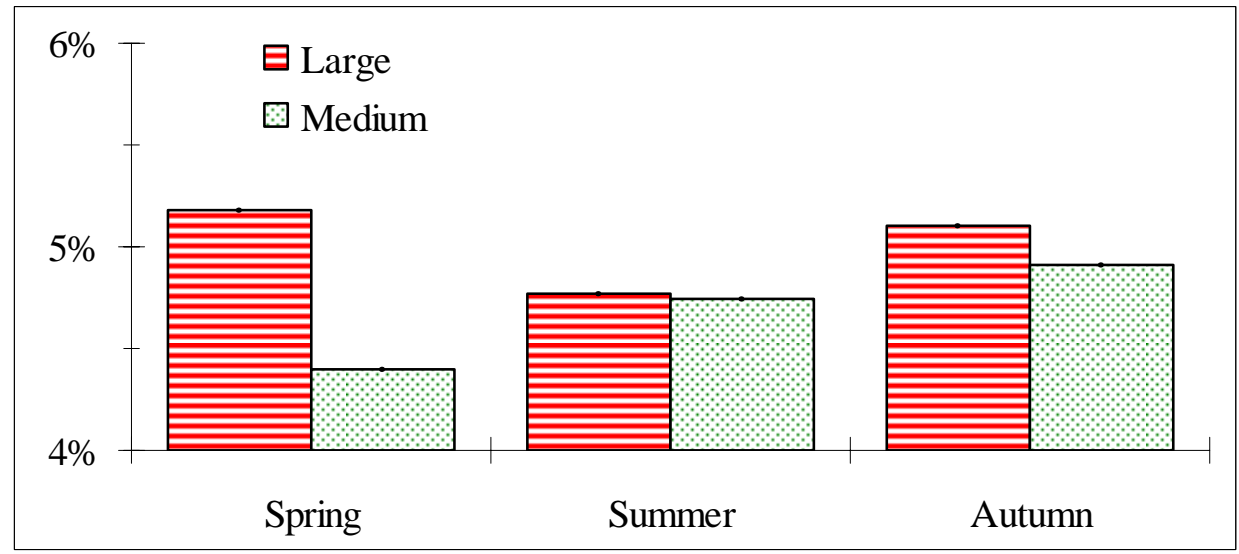

Fig. 9. Lipid content in the striated muscle of scallop juveniles according to the season with standard deviation. $\mathrm{N}=10$ /batch 